\title{
Ringwoodite microstructures in L-chondrite NWA 5011: implications for transformation mechanism and source region in L parent body
}

\author{
Szabolcs Nagy* \\ Department of Petrology and Geochemistry, Institute \\ of Geology, Eötvös Loránd University, Budapest
}

\section{Sándor Józsa}

Department of Petrology and Geochemistry, Institute of Geology, Eötvös Loránd University, Budapest

Department of Materials Physics, Institute of Physics, Cosmic Materials Space Research Group,

Eötvös Loránd University, Budapest

Ildikó Gyollai

Department of Materials Physics, Institute of Physics, Cosmic Materials Space Research Group,

Eötvös Loránd University, Budapest

\section{Szaniszló Bérczi}

Department of Materials Physics, Institute of Physics, Cosmic Materials Space Research Group Eötvös Loránd University, Budapest

Department of Litospheric Research University of Vienna, Vienna

\section{Zsolt Bendő}

Department of Petrology and Geochemistry, Institute

of Geology, Eötvös Loránd University, Budapest

\section{Harald Stehlik}

Wien

Ringwoodite, produced by shock metamorphism, is common in and adjacent to melt veins in highly shocked chondrites. Although ringwoodite can be crystallized from the silicate melt in the shock-veins or pockets, a major part of the easily observed ringwoodite in shock veins is formed by the transformation of olivine in host-rock fragments entrained in the melt or olivine along shock-vein margins. In this paper we examine the microstructures and textures of ringwoodites from NWA 5011 L-chondrite in order to better understanding the transformation mechanisms of ringwoodite by optical microscope. Finally, we attempt to locate the source region of L-type chondrites in three different impact scenarios of the L parent body.

Key words: shock vein, ringwoodite, microstructures, transformation mechanism, NWA 5011, nucleation, growth

\section{Introduction}

It is generally accepted that the melt veins observed in many chondrites were formed by shock loading (Xie and Sharp 2003). Melt veins commonly contain newly crystallized grains of silicate, oxide, sulfide and metal that are (in some cases) accompanied by silicate glass or altered silicate glass. L6 chondrites are the

Addresses: Sz. Nagy, S. Józsa, Zs. Bendő: H-1117 Budapest, Pázmány Péter sétány 1/c, Hungary I. Gyollai, Sz. Bérczi: H-1117 Budapest, Pázmány Péter sétány 1/a, Hungary

H. Stehlik: 3 Hagedornweg 2/12, A-1220 Wien, Austria

*corresponding author e-mail: ringwoodite@gmail.com

Received: November 11, 2011; accepted: November 30, 2011 
major hosts for high-pressure phases including ringwoodite, wadsleyite, magnesiowüstite, akimotoite, majorite-pyrope garnet, jadeite, and hollanditetype structure of plagioclase (Kimura et al. 2003). Ringwoodite is an important indicator of shock stage S6 (40-50 GPa) (Sharp and DeCarlie 2006) because its characteristic blue color can be easily discernible in thin section.

The transformation of olivine to ringwoodite plays a key role in mineralogy because the transformation kinetics can be used to constrain shock duration if one knows P-T conditions and transformation mechanisms. These transformations only occur in materials that are in contact with melt, suggesting that such transformations are only kinetically possible in the highest temperature regions of the sample (Xie et al. 2001; Sharp and DeCarlie 2006). It has been demonstrated that the quenching time is strongly dependent on the thickness of the melt vein and can range from nanosecond to second time scales for $\mu \mathrm{m}$ to $\mathrm{mm}$ thick veins (Langenhorst and Poirier 2000). The pressure and temperature conditions in the shock veins are significantly heterogeneous (even within a grain); therefore it is unambiguous that the crystallization mechanisms could be different for the various pressure and temperature excursions. Shock veins cool by thermal conduction into the surrounding matrix rather than by adiabatic cooling associated with pressure release. Solidification is rapid and strongly dependent on vein thickness (Xie et al. 2001).

\section{Sample and experimental procedure}

The discovery of ringwoodite, the spinel-structured polymorph of olivine, in Tenham (Binns 1970) provided proof that Tenham had experienced high shock pressures of 25-45 GPa (Langenhorst et al. 1995). Numerous other high-pressure minerals have been found in shocked meteorites since the time of ringwoodite and majorite discoveries. These mineral transformations mainly belong to a chondritic class of meteorites, the L-type chondrites.

The NWA 5011 is an L6-type chondrite. It was found in Morocco in 2005. The falling event is not known as well as its location. Entering into the Earth's atmosphere the meteorite was broken into many pieces (probably many hundreds). The weathering rate is intermediate (W3). This means that the sample consists of medium-level secondary minerals such as hematite and/or limonite. The main mineral components are as follows: olivine $\left(\mathrm{Fo}_{80-67}\right)$, orthopyroxene, clinopyroxene, plagioclase (generally in the form of maskelynite), troilite, Fesulfide. The minor and trace components are chromite, magnetite, ilmenite, apatite and whitlockite. NWA 5011 contains shock-induced melt veins (the largest is $7 \mathrm{~mm}$ in width) and nest-like melt pockets (Fig. 1).

The texture of bulk rock is mainly granular with rounded olivine grains, sometimes with a maximal diameter of $1 \mathrm{~cm}$. The bulk rock is heavily shocked; therefore it contains many cracks or fractures. The sample also contains a few well-preserved chondrules of $0.5-4 \mathrm{~cm}$ diameter. 


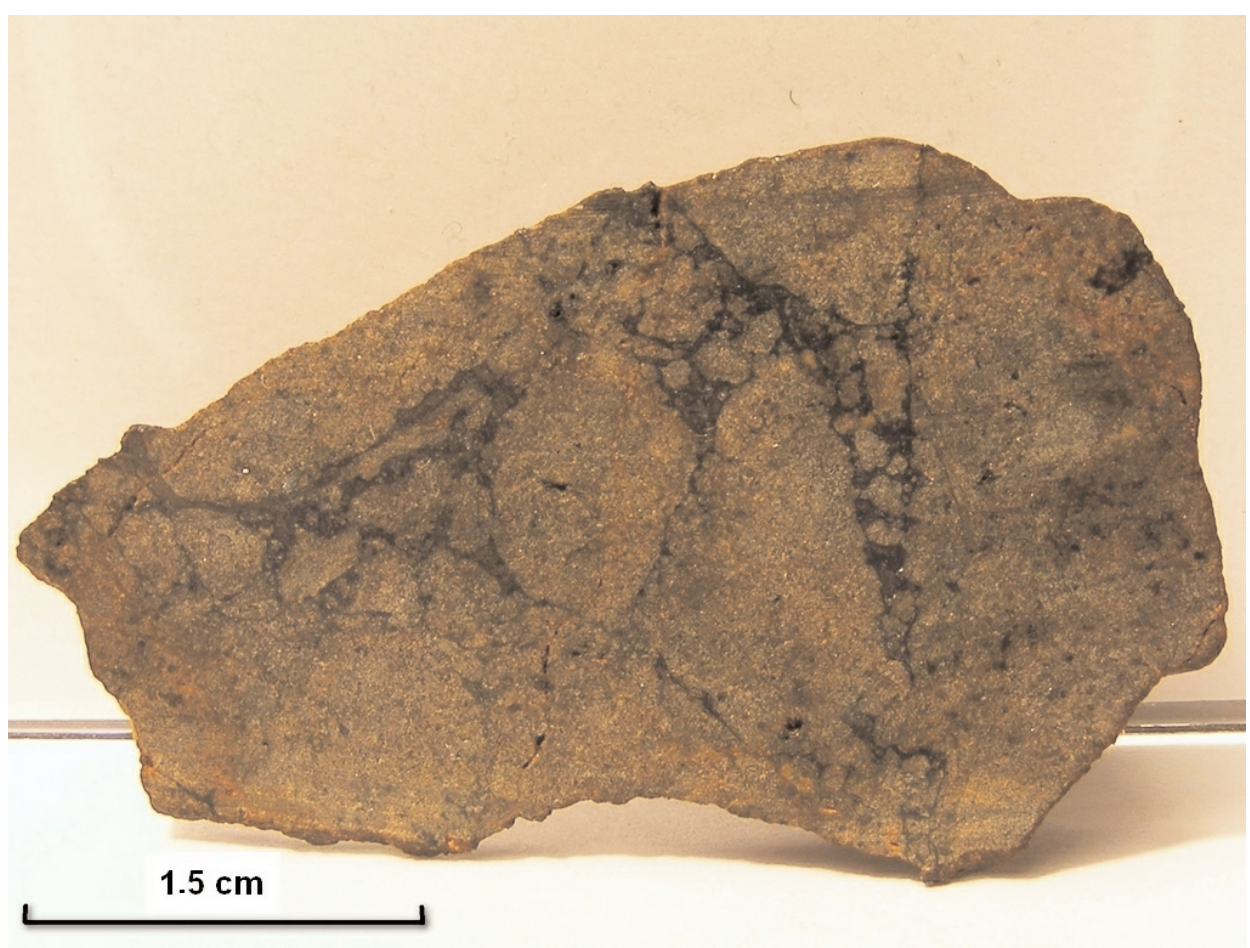

Fig. 1

Hand specimen of NWA 5011. The shock vein network and nest-like melt pockets are clearly seen together and appear as dark areas in this section (Photo: Sz. Nagy)

The investigated thin section from the NWA 5011 meteorite was prepared and polished to $30 \mu \mathrm{m}$ in thickness. The mineral assemblages and texture were characterized with a Nikon Eclipse LV100POL optical microscope in polarized and reflected light modes, respectively. The chemical compositions were determined using an Amray 1830 scanning electron microscope with EDAX PV9800 EDS detector, a beam current of $1 \mathrm{nA}$ and a defocused spot size of 10-50 $\mathrm{nm}$. The collection time was $100 \mathrm{sec}$. For the measurements we used international olivine, pyroxene, and feldspar as standards. Analyses were determined at an accelerating voltage of $20 \mathrm{kV}$. The phases' identification was determined using a Renishaw RM2000 raman spectrometer. The length of detection time was $120 \mathrm{sec}$.

\section{Ringwoodite in shock veins of NWA 5011}

The possibility that olivine might be transformed to a denser spinel structure was first suggested by Bernal (1936), and Jeffreys (1937). Spinel is about 9\% denser than the corresponding olivine (Ringwood and Major 1966). This highpressure olivine polymorph can only be formed in meteorites as a result of a 
shock process. In such an environment crystallization must occur suddenly because of the rapid solidification of shock melt veins. The transformation requires high activation energy in a shocked meteorite; therefore the most favorable places for high pressure polymorphs would be the melt pockets and shear-induced shock melt veins. These locations have the necessary temperature for the reconstructive phase transformation. The remarkable amount of shock veins and melt pockets in shocked meteorites suggest that originally the meteorite had numerous fractures.

The shock veins in NWA 5011 have two main textural units. The first unit can be characterized by the fine-grained matrix, which crystallized from melt under high pressure, and consists mainly of garnet solid-solution phases after pyroxene transformation. The size dimensions of crystals are in the submicron range. The other unit can be determined as large fragments, which includes ringwoodite and other high-pressure mineral phases. The ringwoodite is brought to the solid state transformations along the circumference of shock veins. In some cases, ringwoodite can also be observed inside the vein. The distribution of polycrystalline ringwoodite within the melt veins is homogeneous in spite of the heterogeneous distribution of optically observed blue ringwoodite. The color of ringwoodite varies in meteorites, between different ringwoodite aggregates, and even in a single grain inside one aggregate (which is generally a tiny, single ringwoodite grain) (Lingemann and Stöffler 1999). The ringwoodite aggregates

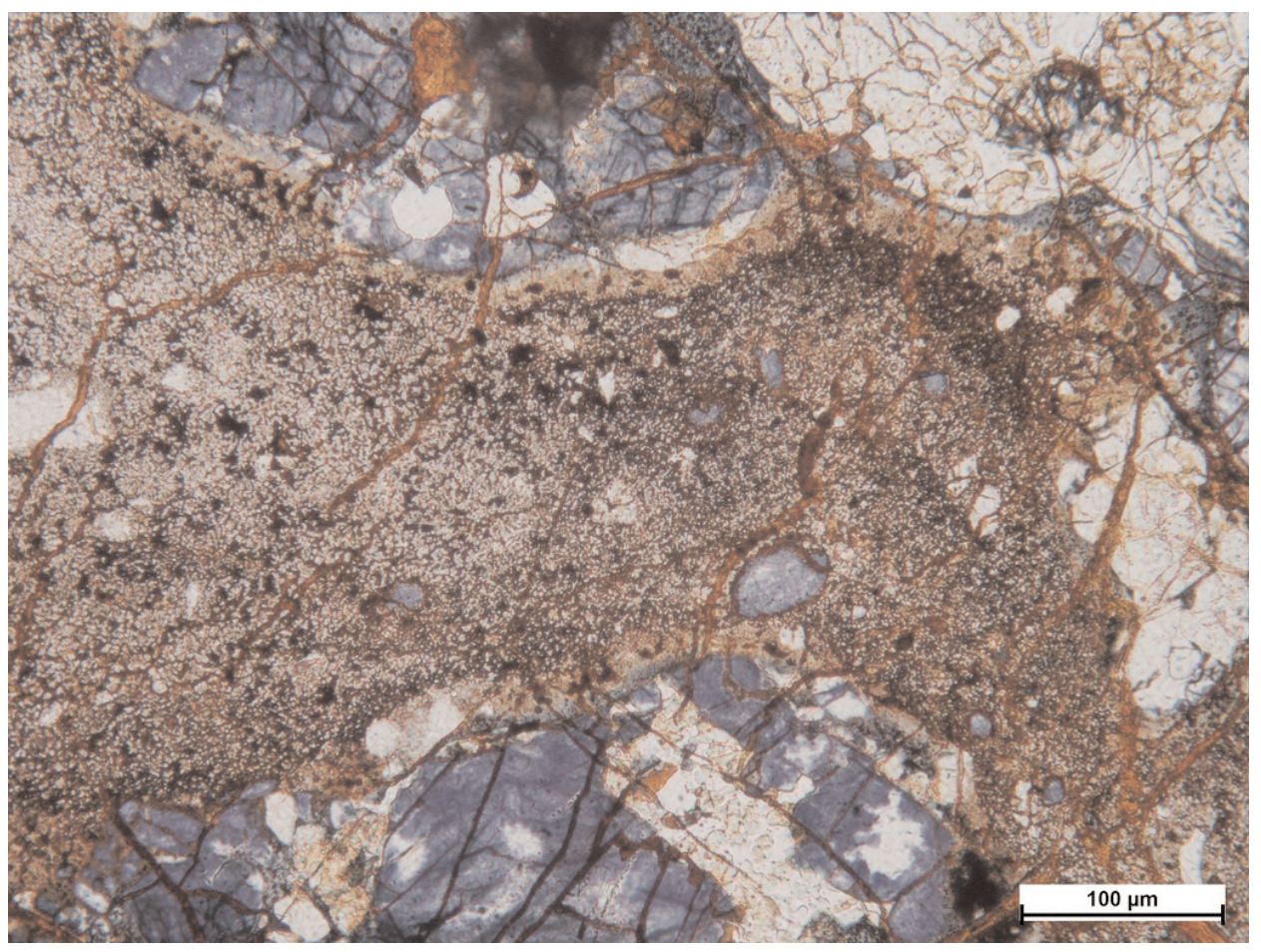

Central European Geology 54, 2011 
Table 1

EMPA analysis of olivine and ringwoodite observed in NWA 5011

\begin{tabular}{|c|c|c|c|c|c|c|}
\hline Oxide & Ol-chon & Ol-lam & Rgt-lam & Rgt-blue & Rgt-cless & Rgt-p. blue \\
\hline $\mathrm{SiO}_{2}$ & 39.73 & 39.74 & 37.54 & 38.08 & 38.65 & 38.73 \\
\hline $\mathrm{TiO}_{2}$ & $?$ & $?$ & $?$ & $?$ & $?$ & $?$ \\
\hline $\mathrm{Al}_{2} \mathrm{O}_{3}$ & $?$ & $?$ & $?$ & $?$ & $?$ & $?$ \\
\hline $\mathrm{FeO}$ & 22.08 & 21.90 & 28.31 & 23.38 & 22.92 & 22.41 \\
\hline $\mathrm{MnO}$ & 0.55 & 0.30 & 0.19 & 0.25 & 0.38 & 0.31 \\
\hline $\mathrm{MgO}$ & 37.55 & 37.88 & 33.79 & 37.54 & 37.63 & 38.24 \\
\hline $\mathrm{NiO}$ & $?$ & $?$ & $?$ & $?$ & $?$ & $?$ \\
\hline $\mathrm{CaO}$ & $?$ & $?$ & $?$ & $?$ & $?$ & $?$ \\
\hline $\mathrm{Na}_{2} \mathrm{O}$ & $?$ & $?$ & $?$ & $?$ & $?$ & $?$ \\
\hline $\mathrm{K}_{2} \mathrm{O}$ & $?$ & $?$ & $?$ & $?$ & $?$ & $?$ \\
\hline $\mathrm{Cr}_{2} \mathrm{O}_{3}$ & $?$ & $?$ & $?$ & $?$ & $?$ & $?$ \\
\hline Total (wt.\%) & 99.91 & 99.81 & 99.84 & 99.24 & 99.59 & 99.70 \\
\hline Formula & & . & & & & \\
\hline $\mathrm{O}=$ & 4 & 4 & 4 & 4 & 4 & 4 \\
\hline $\mathrm{Si}$ & 1.030 & 1.029 & 1.006 & 1.003 & 1.011 & 1.010 \\
\hline $\mathrm{Ti}$ & $?$ & $?$ & $?$ & $?$ & $?$ & $?$ \\
\hline $\mathrm{Al}$ & $?$ & $?$ & $?$ & $?$ & $?$ & $?$ \\
\hline $\mathrm{Fe}^{2+}$ & 0.479 & 0.474 & 0.634 & 0.515 & 0.502 & 0.488 \\
\hline Mn & 0.012 & 0.007 & 0.004 & 0.006 & 0.008 & 0.007 \\
\hline $\mathrm{Mg}$ & 1.450 & 1.462 & 1.344 & 1.474 & 1.468 & 1.486 \\
\hline $\mathrm{Ni}$ & $?$ & $?$ & $?$ & $?$ & $?$ & $?$ \\
\hline $\mathrm{Ca}$ & $?$ & $?$ & $?$ & $?$ & $?$ & $?$ \\
\hline $\mathrm{Na}$ & $?$ & $?$ & $?$ & $?$ & $?$ & $?$ \\
\hline K & $?$ & $?$ & $?$ & $?$ & $?$ & $?$ \\
\hline $\mathrm{Cr}$ & $?$ & $?$ & $?$ & $?$ & $?$ & $?$ \\
\hline Total & 2.971 & 2.972 & 2.988 & 2.998 & 2.989 & 2.991 \\
\hline $\mathrm{Fa}(\mathrm{m} . \%)$ & 25 & 24 & 32 & 26 & 25 & 25 \\
\hline
\end{tabular}

All iron is assumed ferrous. Ol-chon $=$ olivine in chondritic part, Ol-lam $=$ host olivine with ringwoodite lamellae, Rgt-lam $=$ ringwoodite lamellae, Rgt-blue $=$ ringwoodite with blue colour, Rgt-cless = colourless ringwoodite, Rgt-p. blue = ringwoodite with pale blue colour, ? = not determined

$\leftarrow$ Fig. 2

Blue polycrystalline ringwoodite aggregates along the circumference of a shock melt vein from the NWA 5011 chondrite (Photo: Sz. Nagy) 
Table 2

Observed raman peak positions and vibrational modes of olivine and ringwoodite in the NWA 5011 meteorite. The Sixiangkou ringwoodite data were used as reference material (Chen et al. 2006)

\begin{tabular}{|c|c|c|c|}
\hline \multirow[b]{2}{*}{ Peak positions $\left(\mathrm{cm}^{-1}\right)$} & \multicolumn{3}{|c|}{ Minerals } \\
\hline & ol (NWA 5011) & rgt (NWA 5011) & rgt (Sixiangkou) \\
\hline $301(\mathrm{~F} 2 \mathrm{~g})$ & - & - & $x$ \\
\hline $370(\mathrm{~F} 2 \mathrm{~g})$ & - & - & $x$ \\
\hline $535(\mathrm{~F} 2 \mathrm{~g})$ & $x$ & - & - \\
\hline $591(\mathrm{~F} 2 \mathrm{~g})$ & $x$ & - & - \\
\hline $598(\mathrm{~F} 2 \mathrm{~g})$ & - & - & $\times$ \\
\hline 795 (A1g) & - & $x$ & $x$ \\
\hline 822 (A1g) & $x$ & - & - \\
\hline 833 (A1g) & - & $\times$ & - \\
\hline 843 (F2g) & - & $\times$ & $\times$ \\
\hline 852 (A1g) & $x$ & $\times$ & - \\
\hline $875(?)$ & - & $x$ & - \\
\hline $918(\mathrm{~F} 2 \mathrm{~g})$ & $x$ & - & - \\
\hline $952(\mathrm{~F} 2 \mathrm{~g})$ & $\times$ & - & - \\
\hline \multicolumn{4}{|c|}{$\begin{array}{l}\text { ol (NWA } 5011)=\text { olivine in NWA } 5011 \text { meteorite, rgt (NWA 5011) = ringwoodite in } \\
\text { NWA } 5011 \text { meteorite, rgt (Sixiangkou) = ringwoodite in Sixiangkou meteorite. In the } \\
\text { peak positions column the brackets consist of the signs of the raman vibrational modes } \\
\text { as well as } \mathrm{F} 2 \mathrm{~g}=\text { asymmetric streching vibrations of } \mathrm{SiO}_{4} \text { units, } \mathrm{A} 1 \mathrm{~g}=\text { symmetric } \\
\text { streching vibrations of } \mathrm{SiO}_{4} \text { units }\end{array}$} \\
\hline
\end{tabular}

can show every shade of blue, purple, gray, and green, or they may have no color at all (Fig. 2). A closer look at colored aggregates shows the heterogeneous color distribution, which depends on the size of ringwoodite crystallites. In some grains the color of ringwoodite only occurs along thin planes within the aggregates. The EPMA-analyses revealed that the average composition of the polycrystalline ringwoodite aggregates is close to the composition of the olivine in the host chondrite. No significant chemical differences have been found between colorless and colored ringwoodite aggregates or the differently-colored aggregates and host olivine (Table 1). The micro-Raman structural investigations revealed an unknown peak, which does belongs neither to ringwoodite nor to other high-pressure mineral polymorphs (Table 2). This effect comes from those ringwoodite aggregates, which are located in the peripheral part of a thick shock vein. It might be related to lowering symmetry of ringwoodite showed by the increasing number of peaks in the micro-Raman spectrum (Nagy et al. 2010). 


\section{Microstructures of ringwoodite in NWA 5011}

When viewed at high magnification, ringwoodite has a granular texture that we interpret to be the actual crystal size in the polycrystalline aggregate. This implies that NWA 5011 has ringwoodite crystallites in excess of $10 \mu \mathrm{m}$ in size (Fig. $3)$. The blue color is clearly associated with grain boundaries in these polycrystalline aggregates, with the darkest blue colors corresponding to the finest grained ringwoodite. The color variation in NWA 5011 commonly occurs in the form of planar bands of dark blue ringwoodite that correspond to planar concentrations of submicron size crystallites. In some polycrystalline ringwoodite aggregates that are composed of very fine-grained crystallites the individual crystallites are of nanometer size. Their occurrence together with larger individual ringwoodite grains is supposed to show the different transformation mechanism within a ringwoodite assemblage. A partially transformed texture was also found in some olivine grains which were located close to the vein edge. In some cases ringwoodites appeared as lamellae, as it is shown in optical and reflected light images (Figs 4 and 5); this was first published by Chen et al. (2004). The lamellae system shows at least three different orientations in a given section,

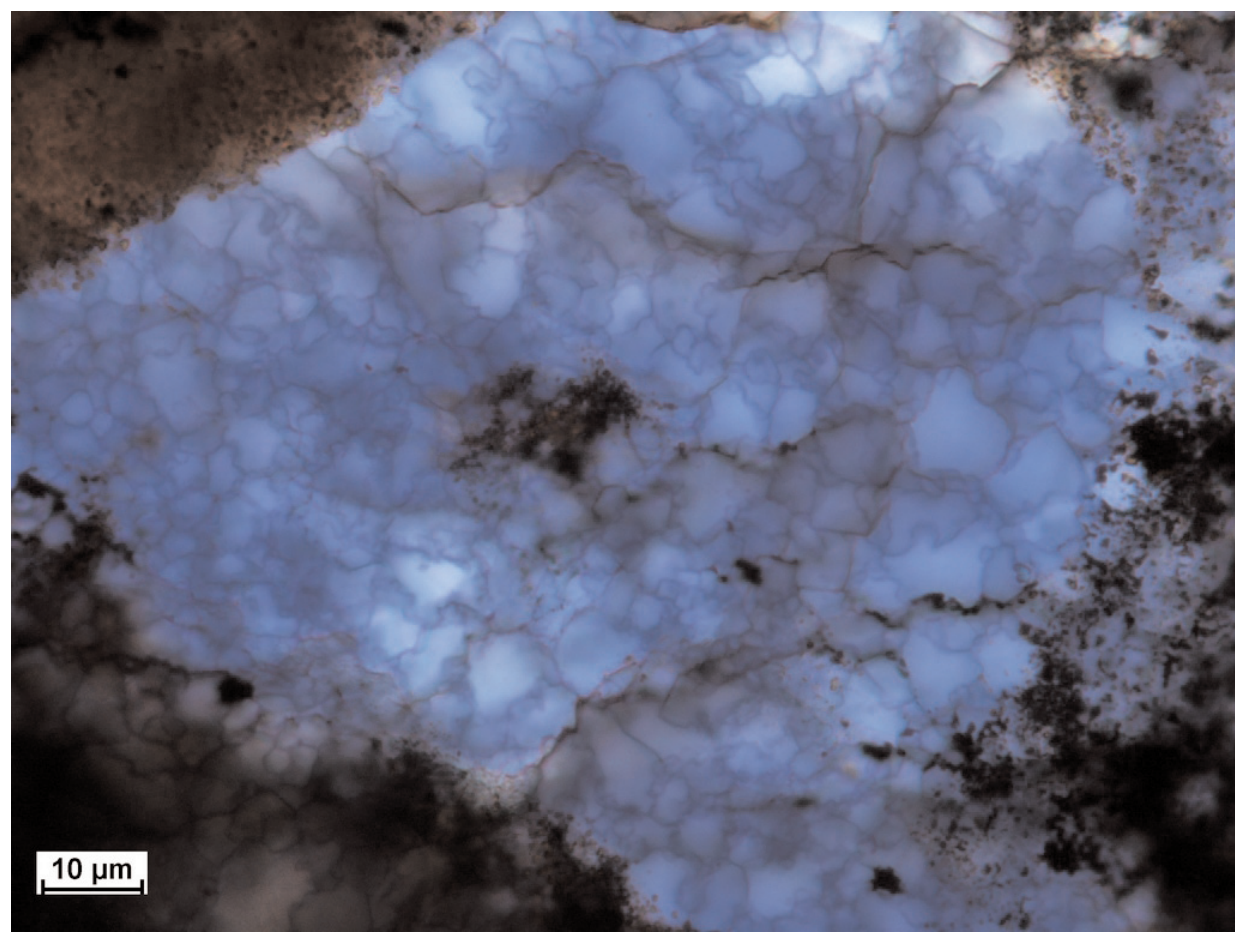

Fig. 3

Plane-polarized light micrograph of a ringwoodite aggregate in NWA 5011. The dark blue color is associated with the grain boundaries. The dark areas are opaque minerals (Photo: Sz. Nagy) 


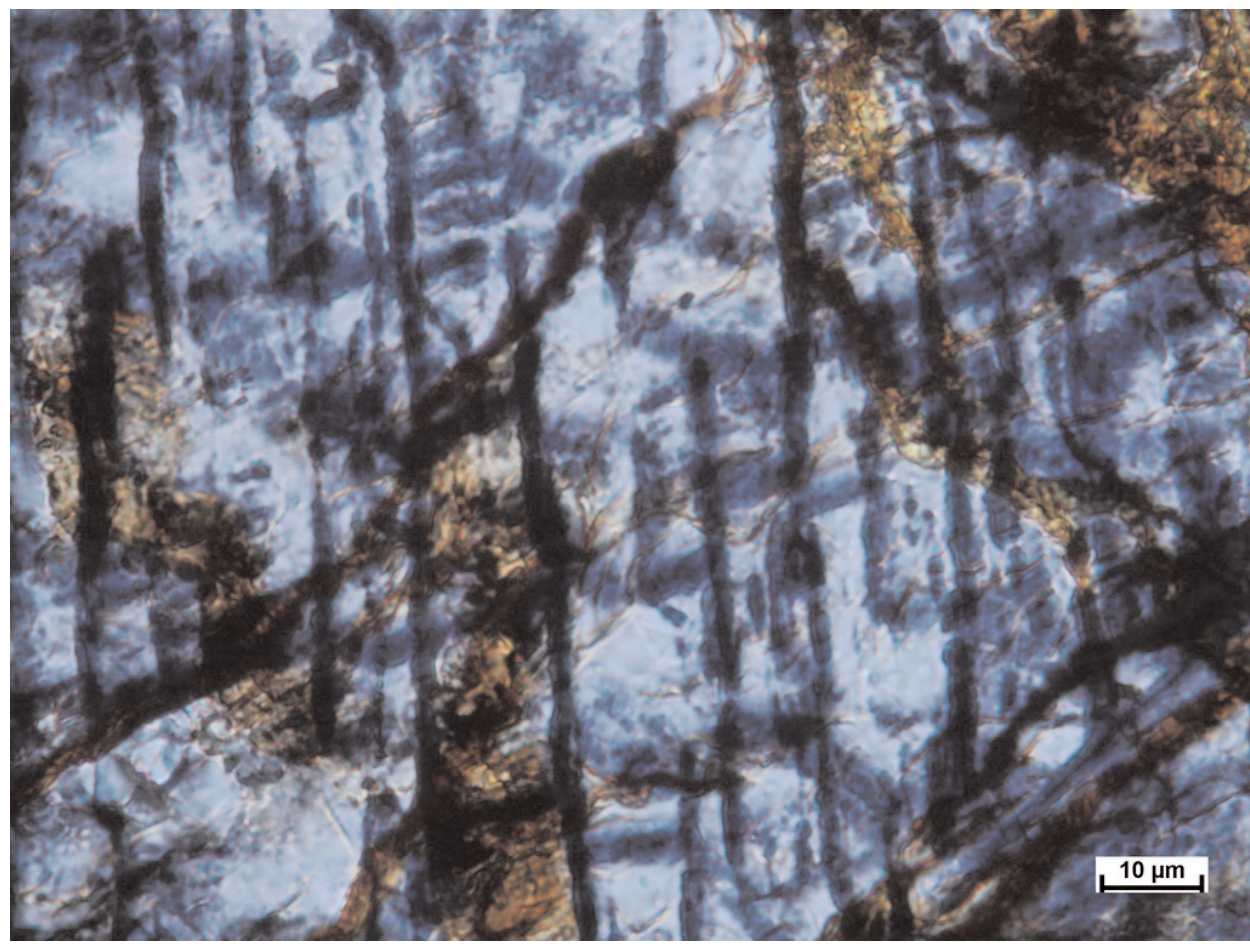

Fig. 4

Plane polarized light image of ringwoodite lamellae in olivine (Photo: Sz. Nagy)

which might have corresponded to rational crystallographic planes of olivine. In these lamellae the ringwoodite is relatively coarse-grained and is of pale blue color. Chemical analysis determined that these ringwoodite lamellae are significantly enriched in iron to correlate with the host olivine (Table 1).

\section{Possible olivine-ringwoodite solid-state transformation mechanisms on the base of observed microstructures}

The mechanisms by which low-pressure minerals are transformed into their high-pressure polymorphs during shock events are important for understanding the kinetics of shock effects. The transformation of minerals to their highpressure polymorphs can be described by following mechanisms: displacive, reconstructive, or martensitic-like mechanisms.

In a displacive phase transformation the structural difference between the polymorphs is small. This transition is nonquenchable, indicating that the highpressure polymorph will spontaneously transform to the low-pressure polymorph upon pressure release. 


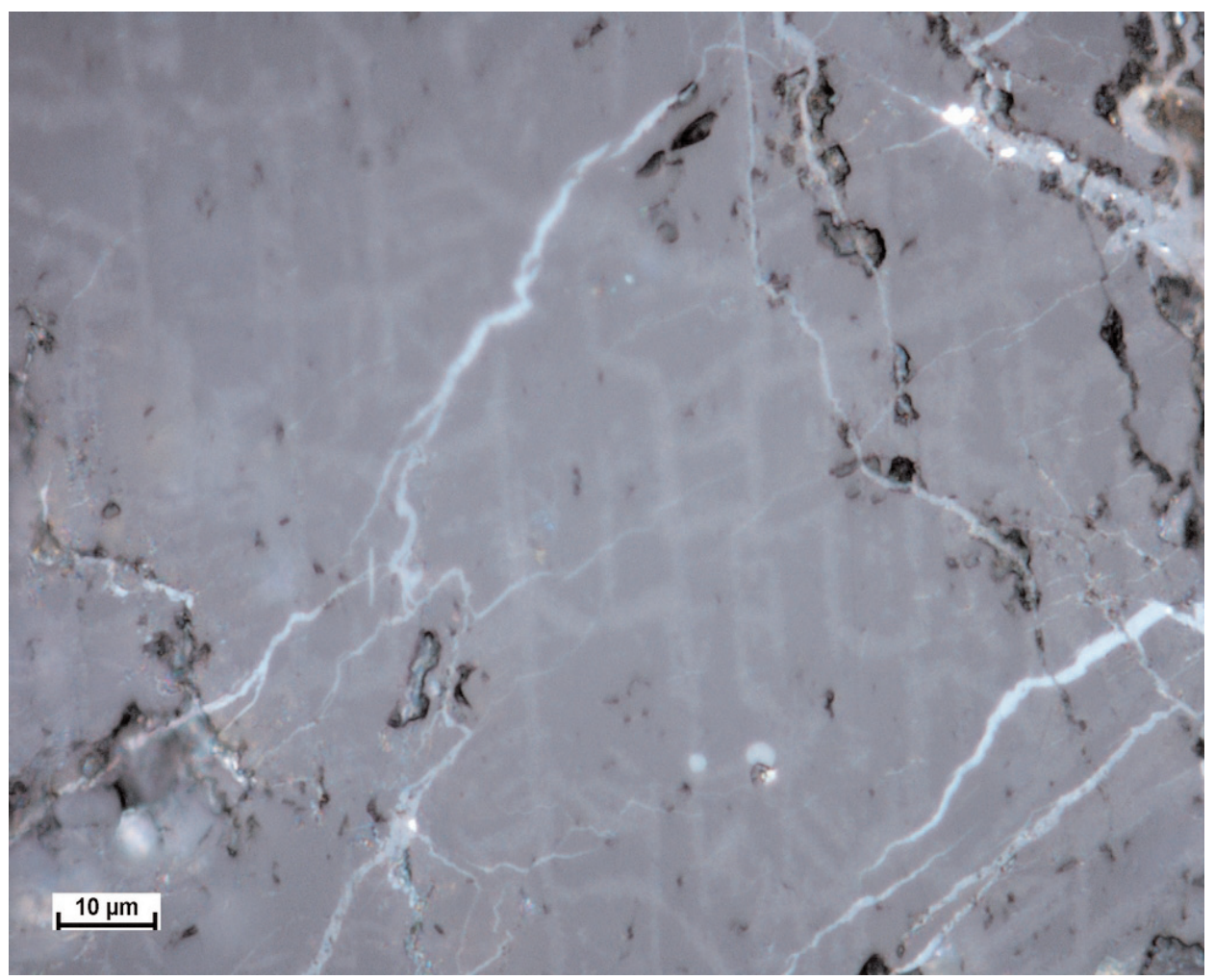

Fig. 5

Reflected light image in the same area of Figure 4. At least three lamella orientations can be observed in this section (Photo: Sz. Nagy)

The reconstructive phase transition involves substantial change in crystal structure, that is, the breaking of the bonds and formation of new bonds (Sharp and DeCarlie 2006). This type of transition requires high activation energy, and generally also high temperatures; it occurs by nucleation and growth. Nucleation can occur homogeneously throughout the crystal of the parent phase, or it can occur heterogeneously at defective sites or grain boundaries of the parent phase. If the new phase has a chemical composition that is different from that of the initial phase, then growth of the new phase is known as diffusion-controlled because the transformation rate is limited by rates of long-range diffusion.

In a martensitic phase transformation the mechanism does not involve nucleation and growth, but rather the rearrangement of atom positions by shearing. In this case, shearing results from the passage of partial dislocations and the product phase is related to the initial phase by a series of stacking faults.

Different techniques generally show randomly oriented ringwoodite crystallites within an aggregate (Putnis and Price 1979). The random orientations 


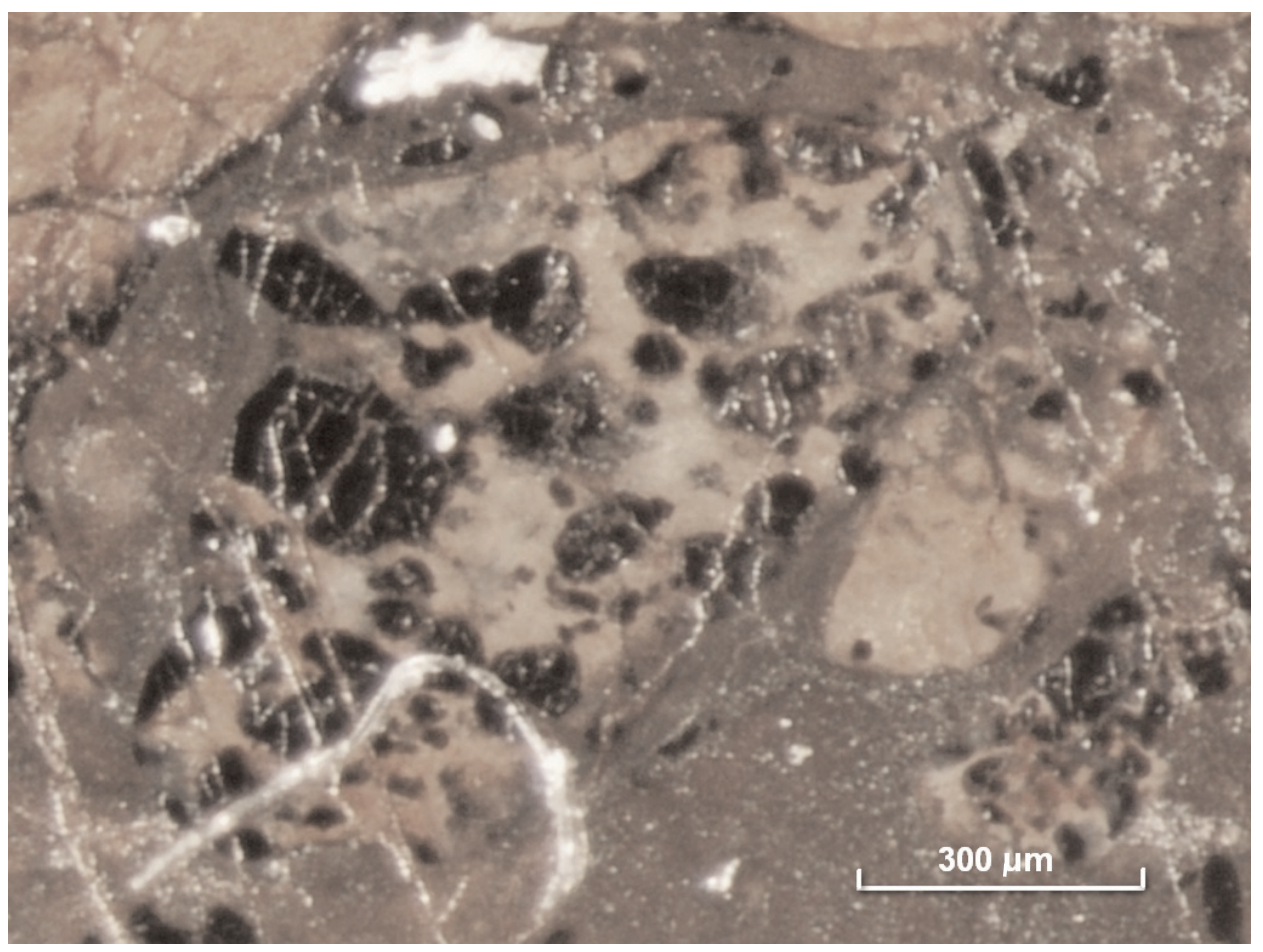

Fig. 6

A very thick shock melt vein in NWA 5011. This binocular photo shows the distribution of ringwoodites (most of the dark grains) within the melt vein (Photo: Sz. Nagy)

and homogeneous distribution of ringwoodite crystallites suggest homogeneous intracrystalline nucleation throughout the olivine rather than heterogeneous nucleation on grain boundaries, which is the dominant mechanism at pressures closer to the equilibrium phase boundary (Kerschhofer et al. 2000). In most samples the ringwoodite composition is constant, implying that there was no $\mathrm{Fe}-$ $\mathrm{Mg}$ exchange during the transformation and therefore the crystallites grew by interface-controlled growth. In our ringwoodite the lamellae have significantly higher fayalite content then the surrounding olivine, suggesting a diffusioncontrolled growth mechanism. Kerschhofer et al. (1996) discovered a new intracrystalline mechanism that involved the formation of stacking faults in olivine on (100), followed by the nucleation of ringwoodite lamellae on the stacking faults. We must index the differently oriented lamellae in order to determine the new Kerschhofer's intracrystalline mechanism on stacking faults. In the experiments, iron enrichment was not observed in the lamellae. The fracture-induced transformation (which is a subgroup of the reconstructive transformations) allows implying diffusion-controlled mechanism, as has been suggested in the case of the Sixiangkou meteorite (Chen et al. 2006). It has been 
shown that the boundary zone of lamellae and host grain interface areas were enriched in $\mathrm{Mg}$ and $\mathrm{Fe}$, respectively, which is in good agreement with our observations. In the case of ringwoodite aggregates, which showed submicron size crystallites, martensitic-like transformation mechanism could have been interpreted. The other possibility for interpretation for the submicron-sized crystal aggregates may be the difference in heat distribution corresponding to the formation of nuclei within the aggregate (Miyahara et al. 2010) (Fig. 7).

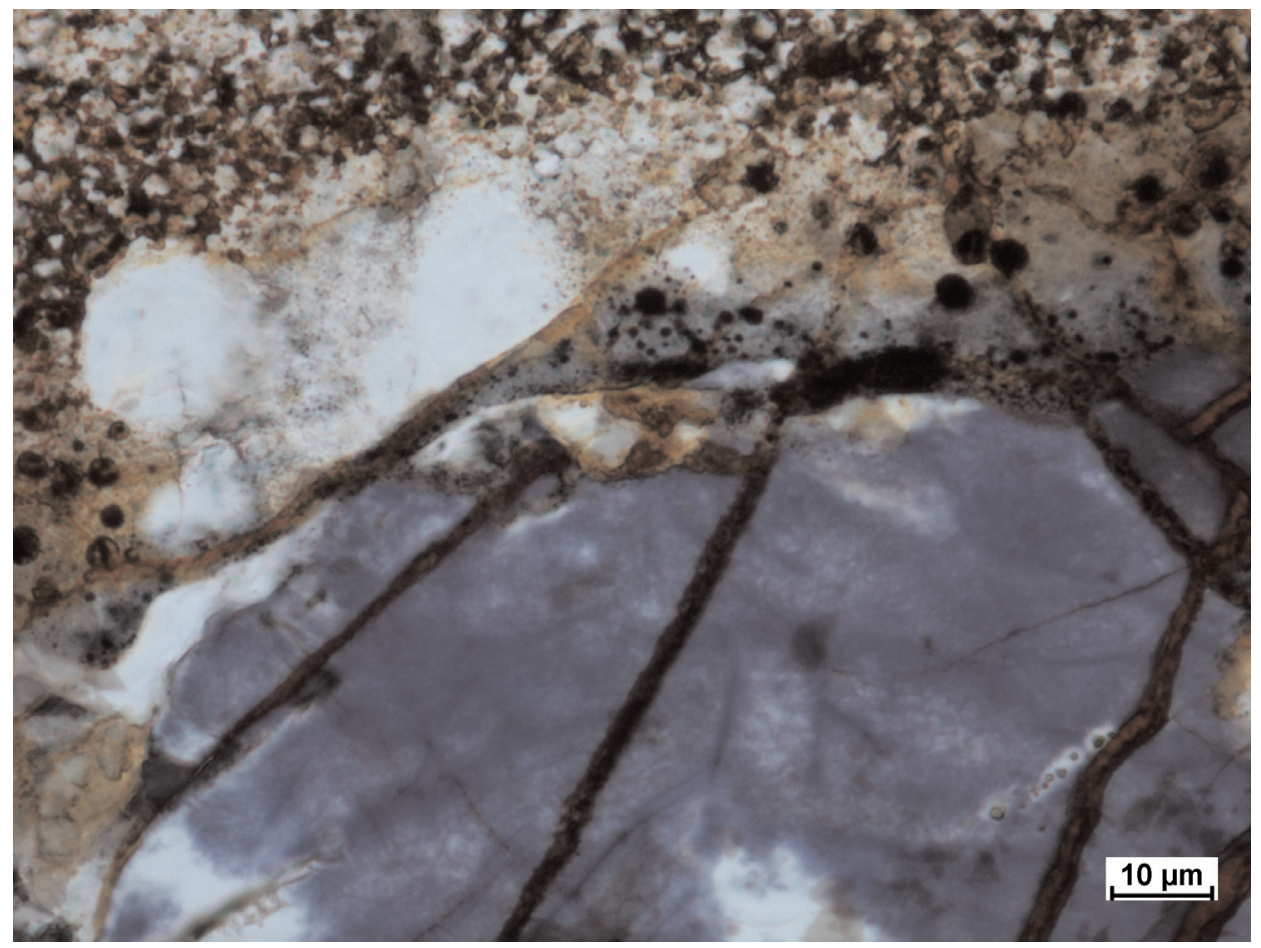

Fig. 7

This photo shows different homogeneous intracrystalline nucleation and growth areas, where the nucleation rates were significantly variant. This may prove the heterogeneous heat distribution within this aggregate. The heterogeneous intracrystalline nucleation and growth area can be seen on the right side of the photo at the scale bar. In this latter case the ringwoodite nuclei were formed around incoherent inclusions (Photo: Sz. Nagy)

In some partially transformed olivine-ringwoodite assemblages, the nucleation trend may be determinable. Optical investigations revealed that in such form of olivine-ringwoodite aggregates, transition begins at the brink of circumference of the aggregate and persists toward the center. The direction of transformation is from outside inward because the center of some aggregate occurrences consists of olivine, which shows that the process is a prograding one. From the shock melt vein margin we observed three distinct olivine-ringwoodite textures: (1) 
polycrystalline ringwoodite, (2) several oriented sets of ringwoodite lamellae and (3) oriented single lamellae.

The individual ringwoodite grains are of very different size, even within an assemblage. This heterogeneous size distribution suggests that the temperature distribution was very heterogeneous within the previous olivine grain. If the temperature difference between a part of host olivine grain and the surrounding melt vein area was high, nucleation process superceded the crystal growth one. In contrast to this, if the deviation of temperature between a part of host grain and the surrounding melt vein area was small, the growth process significantly overrode nucleation.

There is a problem in the case of the reconstructive transformation, when the intracrystalline nucleation mechanism is used for olivine. The question is: what are the characteristic conditions for olivine during the transformation? If the olivine is characterized by diaplectic condition (just as maskelynite is in the case of plagioclase), this would require enormous shock pressure: about 55 GPa or higher (Jeanloz et al. 1977). At this pressure the plagioclase should vesiculate in the bulk rock. But the maskelynite does not show vesiculation or melting in the chondritic part of NWA 5011. Therefore the shock pressure did not reach $45 \mathrm{GPa}$, which is also in good agreement with the previously published studies on the similar L6 and S6 chondrite samples of Sixiangkou (Wang et al. 1997). Consequently phase transition was rapid and was completed before pressure release. Temperature quenching was more rapid than pressure because of the lack of lower-pressure $(\mathrm{Mg}, \mathrm{Fe})_{2} \mathrm{SiO}_{4}$ phases. Nucleation and growth mechanism probably did not take place in olivine melt under high pressure (except for a few cases) because its shape was not favorable to transition of olivine-ringwoodite from a disordered condition in the very short time scale, and there is no evidence of olivine melt in texture details (Fig. 6). This interpretation is supported by the observation that the original fracture system of the grain has been preserved. The fact that olivine does not transform at very high pressures in diamond anvil experiments without being heated to very high temperatures further supports the idea that high temperatures actually control the distribution of olivine highpressure polymorphs in chondrites.

\section{The source region of the NWA 5011 within the L parent body}

Our NWA 5011 L6 sample belongs to the most populated petrologic type among the L chondrites. (Mócs, a very highly broken up (ca. 3000 pieces) meteorite which fell on Hungary in the 19th century also belongs to this group.) The L chondrite samples are heavily shocked, and an extended shower of L chondrites in the Ordovician was also identified (Greenwood et al. 2007). Due to their heavily shocked character the L chondrites are thought to have originated from the disruption of an asteroid. The disruption time (470 Ma) is in good agreement with that of the Ordovician shower (467 Ma). 


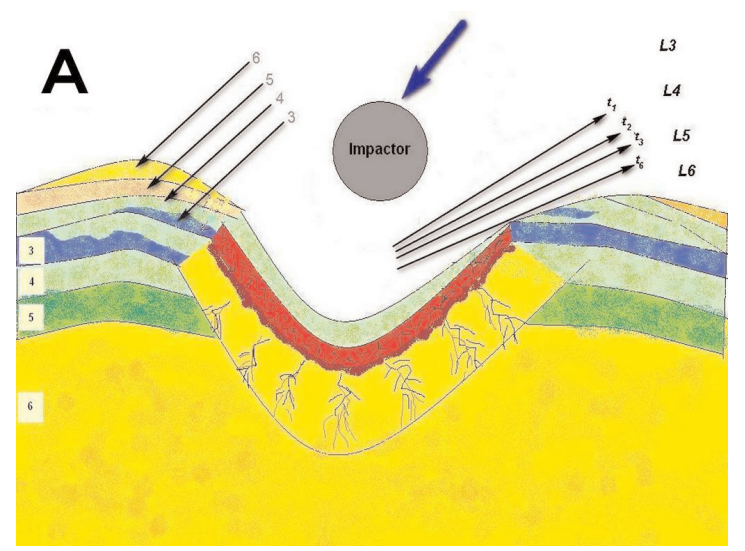

Fig. 8

Events at the onion-shelled L asteroid are suggested. A., Scenario 1: The impactor is a smaller body causing an impact crater. The left side of the figure shows the original layering and the impact causing inverse sedimentological deposition.

B., Scenario 2: A larger impactor almost disrupted the parent body. The numbers show the L3-6-type layers within the parent body.

C., Scenario 3: An even larger impactor disrupts the $\mathrm{L}$ parent body and produces great number of L6 fragments. The arrows roughly show the transport of fragmented material in B and C
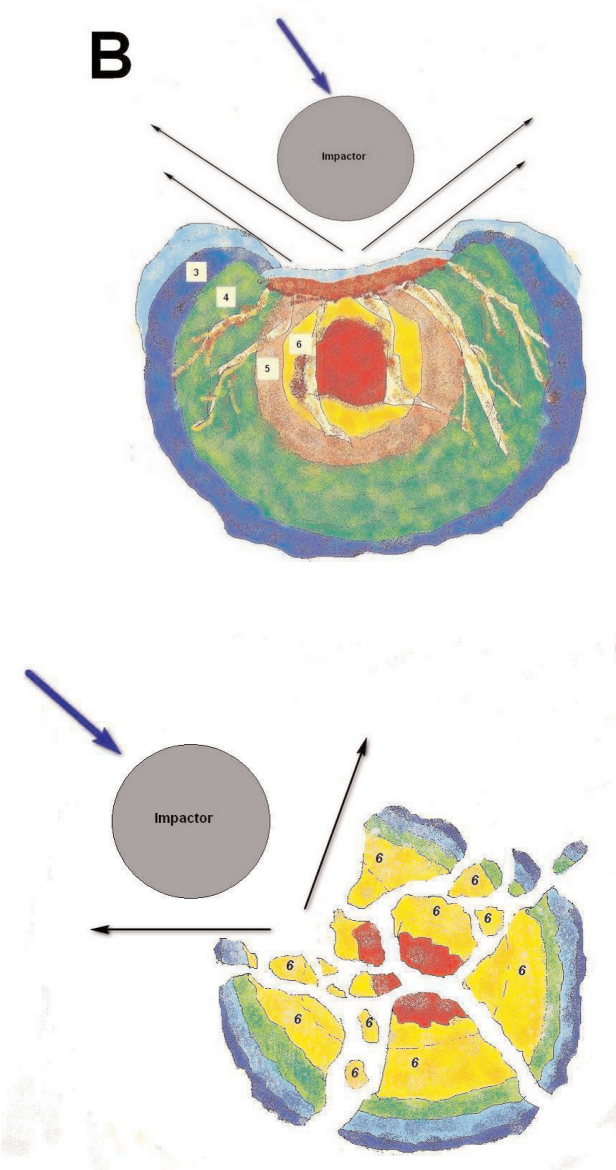
On the basis of the observed structural characteristics of the NWA 5011 chondrite we postulated 3 scenarios concerning its origin. They can be distinguished by the ratio of the diameter of impactor and parent body. The details are shown in Fig. 8. An onion-type L-asteroid is suggested as initial host, with outer normal layering of L3, L4, L5 and L6 layers from top to down direction. The left side of Figure 8/A shows the surface layers; Fig. 8/B shows the asteroid-sized scale of these outer layers, and the inner layers of PA - primitive achondrites, MA - partially melted and iron enriched regions in the center, which is represented by the red-colored area.

\section{1st scenario}

The impactor is a smaller body causing an impact crater on the surface of the $\mathrm{L}$ parent body (Fig. 8/A). In this case a reversal of the order of the original layers form the ring crest of the crater occurs, and there is a low probability of achieving the known frequency of the L chondrites, with $60 \%$ of L6.

\section{2nd scenario}

The impactor is a larger body causing a large impact crater on the surface of the L parent body (Fig. 8/B). The impact almost disrupts the parent body and the impact-generated fissures criss-cross it. Such a large crater, compared to the asteroid diameter, was observed on the asteroid Vesta. This impact causes a larger number of L6 types in the broken and escaping materials.

\section{3rd scenario}

The impactor is even larger body causing disrupting impact on the L parent body (Fig. 8/C). At the breaking edges larger amounts of L6 type fragments escape. Some pieces of the known primitive achondrites and stony-irons may also be related to this disruption.

Our studies left open the possibilities of the 2nd and 3rd scenarios.

\section{Summary and conclusion}

The NWA 5011 chondrite is a very highly shocked meteorite. It contains shockinduced melt veins with a range of variable thickness. These veins contain highpressure olivine polymorphs. The ringwoodite shows different colors in our thin sections. Earlier studies did not find significant differences in chemical composition between the ringwoodite and the host olivine. The ringwoodite microstructure reflects various formation mechanisms, even within an aggregate. The steps of the main transformation mechanisms are intracrystalline nucleation and growth, crack or fracture-induced, martensitic-like, and diffusion-controlled 
nucleations. We have observed unique ringwoodite lamellae microstructure in some olivine grains, which might have had complex transformation mechanisms.

Finally, it was considered that olivine might have been able to survive metastably in the wedge-shaped region within the cold, subducting lithospheric slabs at depths between 400 and $700 \mathrm{~km}$ in the Earth (Frohlich 1994). The described transformation mechanisms and observed microstructural characteristics for olivine-ringwoodite transition suggest that all olivineringwoodite phase transition mechanisms could probably occur in different regions in the same subducting slab, where different degrees of stress and temperature prevail.

\section{Aknowledgements}

The authors are grateful to Csaba Szabó (Eötvös Loránd University, Budapest) for access to the polarization microscope, and to Miklós Veres (KFKI-SZFKI) for assistance in the phase identification process.

\section{References}

Bernal, J.D. 1936: Hypothesis on $20^{\circ}$ discontinuity. Geophysical discussion. - Observatory, 59, 268 p. Binns, R.A. 1970: (Mg,Fe)2SiO4 Spinel in a Meteorite. - Physics of Earth and Planetary Interiors, 3, pp. 156-160.

Chen, M., A. El Goresy, P. Gillet 2004: Ringwoodite lamellae in olivine: Clues to olivine-ringwoodite phase transition mechanisms in shocked meteorites and subducting slabs. - Proc. Natl. Acad. Sci. U.S., 101, pp. 15033-15037.

Chen, M., H. Li, A. El Goresy, J. Liu, X. Xie 2006: Fracture-related intracrystalline transformation of olivine to ringwoodite in the shocked Sixiangkou meteorite. - Meteoritics and Planetary Science, 41, pp. 731-737.

Frohlich, C. 1994: A break in the deep. - Nature, 368, pp. 100-101.

Greenwood, R., C.B. Schmitz, J.C. Bridges, R. Hutchison, I.A. Franchi 2007: Disruption of the L chondrite parent body: New oxygen isotope evidence from Ordovician relict chromite grains. Earth and Planetary Science Letters, 262, 1-2, pp. 204-213.

Jeanloz, R., T.J. Ahrens, J.S. Lally, G.L. Nord, J.M. Christie, A.H. Heuer 1977: Shock-produced olivine glass: First observation. - Science, 97, pp. 457-459.

Jeffreys, H. 1937: On the Materials and Density of the Earth's Crust. - Mon. Not. Roy. Astron. Soc. Geophys. Suppl., 4, pp. 50-61.

Kerschhofer, L., T.G. Sharp, D.C. Rubie 1996: Intracrystalline transformation of olivine to wadsleyite and ringwoodite under subduction zone conditions. - Science, 274, pp. 79-81.

Kerschhofer, L., D.C. Rubie, T.G. Sharp, J.D.C. McConnell, C. Dupas Bruzek 2000: Kinetics of intracrystalline olivine-ringwoodite transformation. - Physics of Earth and Planetary Interior, 121, pp. 59-76.

Kimura, M., M. Chen, Y. Yoshida, A. El Goresy, E. Ohtani 2003: Back-transformation of highpressure phases in a shock melt vein of an $\mathrm{H}$-chondrite during atmospheric passage: Implications for the survival of high-pressure phases after decompression. - Earth and Planetary Science Letters, 217, pp. 141-150.

Langenhorst, F., P. Joreau, J.C. Doukhan 1995: Thermal and shock metamorphism of the Tenham chondrite: A TEM examination. - Geochimica et Cosmochimica Acta, 59, pp. 1835-1845. 
Langenhorst, F, J.P. Poirier 2000: Anatomy of black veins in Zagami: Clues to the formation of highpressure phases. Earth and Planetary Science Letters, 184, pp. 37-55.

Lingemann, C.M., D. Stöffler 1999: New evidence for the colouration and formation of ringwoodite in severely shocked chondrites. - 29th Lunar and Planetary Science Conference. \#1308.

Miyahara, M., E. Ohtani, M. Kimura, A. El Goresy, S. Ozawa, T. Nagase, M. Mnishijima, K. Hiraga 2010: Coherent and subsequent incoherent ringwoodite growth in olivine of shocked L6 chondrites. - Earth and Planetary Science Letters 295, pp. 321-327.

Nagy, Sz., Sz. Bérczi, S. Józsa, A. Gucsik, M. Veres 2010: Olivine and pyroxene high-pressure polymorphs in melt veins of the strongly shocked NWA 5011 meteorite sample. - 41st Lunar and Planetary Science Conference, \#1228.

Putnis, A., G.D. Price 1979: High-pressure $(\mathrm{Mg}, \mathrm{Fe})_{2} \mathrm{SiO}_{4}$ phases in the Tenham chondritic meteorite. - Nature, 280, pp. 217-218.

Ringwood, A.E., A. Major 1966: Synthesis of $\mathrm{Mg}_{2} \mathrm{SiO}_{4}-\mathrm{Fe}_{2} \mathrm{SiO}_{4}$ spinel solid solutions. - Earth and Planetary Science Letters, 1, pp. 241-245.

Sharp, T.G., P.S. DeCarlie 2006: Shock effects in meteorites. - In: Lauretta, D.S., H.Y. McSween (Eds): Meteorites and the early solar system II, Tucson: The University of Arizona Press. pp. 653-677.

Wang, H.N., C.Y. Lin, F.S. Zhang, H.Z. Xu 1997: Shock-metamorphism in Sixiangkou Chondrite from China. - 27th Lunar and Planetary Science Conference, \#1373.

Xie, X., M. Chen, C. Dai, A. El Goresy, P. Gillet. 2001: A comparative study of naturally and experimentally shocked chondrites. - Earth and Planetary Science Letters, 187, pp. 345-356.

Xie, Z., N. Tomioka, T.G. Sharp 2001: High-pressure phases in shock-induced melt veins from the Umbarger L6 chondrite: Constraints on shock conditions. - 32nd Lunar and Planetary Science Conference, \#1805.

Xie, Z., T.G. Sharp 2003: TEM observations of amorphized silicate-perovskite, akimotoite and Ca-rich majorite in a shock-induced melt vein in the Tenham L6 chondrite. - 34th Lunar and Planetary Science Conference, \#1469. 